\title{
Thermal - insulation material for frame panels with an internal non-metallic layer
}

\author{
Boris Aksenov ${ }^{1}$, Oleg Stepanov ${ }^{1}$, and Ludmila Stefurak ${ }^{1 *}$ \\ ${ }^{1}$ Industrial University of Tyumen, Volodarskogo str. 38, Tyumen, 625001, Russia,
}

\begin{abstract}
The foam plastic capable to work in frame panels as a thermal insulation and facing and decorative material can be only of composite type. We have developed a new type of composite foam plastic, its density increases from center to surfaces. The article presents the composition of new material, the technology of its production, as well as the mathematical model of the mechanism of formation of strong crusts at its surfaces. Microscopic analysis of the composite showed that the density of crust is more than $200 \mathrm{~kg} / \mathrm{m}^{3}$, the density of the foam plastic in its middle part is 80 $\mathrm{kg} / \mathrm{m}^{3}$. The limit of strength at punching it by the rod diameter $0.01 \mathrm{~m}$ reaches $3.5 \mathrm{MPa}$. The material is used for the manufacture of roofing panels, frame panels with an internal non-metallic layer.
\end{abstract}

\section{Introduction}

The complete-block method of construction became the main one in arrangement of West Siberian deposits [1]. Especially increases the importance of the construction in frame-panel version, but with the use of powerful bases with the installed equipment. The crucial feature of such buildings is thermophysical parameters base and walling [2, 3, 4].

The three-layered panels frame type need metal for facing-decoration. In the production of double-layer panels the metal consumption can be reduced at least twice. Double-layer and even «metal-free» panels can be manufactured only on high-strength insulation.

At the existing level of panel production technology, only the thermal insulation properties of foams are useful, such an important indicator as strength is not used. The strength of the panels is provided exclusively by structural elements. For example, the steel frame of the panel is sheathed with steel (aluminum, asbestos cement) sheets and filled with foam or mineral wool plates. This leads to a rise in price of panels and deterioration of their thermal performance $[5,6]$. Structurally these disadvantages are difficult to offset.

The development of science and technology of foam plastics production has led to the emergence of new ways to influence the final properties of foam in the process of their formation. On the basis of the multidimensional network model, a model of technical evolution of panel samples was developed, which differ from the existing best technical and economic indicators $[7,8]$.

\footnotetext{
*Corresponding author: stefurak@yandex.ru
} 
As source materials were considered insulation of the high technical level, manufactured in the Russian Federation from domestic raw materials: foams FRV-1, FPB-M, FL1, Vilares; compositional materials: PSF-VNIIST, perlite-foam, keramzit-phenolic-foam and perlitofosfogel $[9,10,11]$. As a result of the analysis and synthesis of a set of elementary functions, a number of hypothetical compositions were created, which were then realized in laboratory and experimental-industrial conditions. Optimization of compositions was carried out by simplex planning $[10,12]$. It was found that the foam plastic capable to work in the panel as a thermal - insulation and facing and decorative material can be only of composite type [1].

We have developed a new type of composite foam plastic (PP), it has a pronounced integral structure: the density increases from center to surface due to the formation of a hard crust.

This paper presents the composition of new material, the technology of its production, as well as the mathematical model for mechanism of formation strong crusts at its surfaces.

\section{Experimental investigation}

As a binder for PP foam plastic is used resin FRV-1A, which in its properties corresponds to TU6-05-1104-78.

Phenol-formaldehyde resin FRV-1A is a homogeneous mixture of neutralized aqueous solution of the primary products of alkaline condensation of phenol and formaldehyde, which introduced surface-active substance OP-7 or OP-10 and aluminum powder in the following ratio in parts by weight:

$\begin{array}{ll}\text { Resin FRV-1A } & -100 \\ \text { Aluminum powder } & -1 \\ \text { OP -7 (OP -10) } & -3\end{array}$

The dynamic viscosity $\eta,\left(N \cdot s / m^{2}\right)$ of the polymer FRV-1A is shown in Table 1.

Table 1 The dynamic viscosity of the polymer FRV-1A

\begin{tabular}{|c|c|c|c|c|c|c|c|}
\hline № parties & $20\left[{ }^{\circ} \mathrm{C}\right]$ & $25\left[{ }^{\circ} \mathrm{C}\right]$ & $30\left[{ }^{\circ} \mathrm{C}\right]$ & $35\left[{ }^{\circ} \mathrm{C}\right]$ & $40\left[{ }^{\circ} \mathrm{C}\right]$ & $45\left[{ }^{\circ} \mathrm{C}\right]$ & $50\left[{ }^{\circ} \mathrm{C}\right]$ \\
\hline 1 & 1.80 & 1.58 & 1.01 & 0.65 & 0.43 & 0.28 & 0.18 \\
\hline 2 & 3.52 & 2.10 & 1.25 & 0.82 & 0.59 & 0.38 & 0.23 \\
\hline
\end{tabular}

Product VAH-3 must comply with the requirements of TU 6-05-1116-78.

The polystyrene shall conform to the requirements of GOST 6-05-202-83. Bulk weight of polystyrene granules is not more than $15 \mathrm{~kg} / \mathrm{m}^{3}$.

Exfoliated vermiculite, free-flowing granular material has flaked structure. Vermiculite the chemical composition is a silicate of magnesium and iron. Vermiculite according to GOST 12865-67 is heterogeneous in composition and has an ellipsoidal configuration, its density $2,52 \cdot 10^{3}-2,86 \cdot 10^{3} \mathrm{~kg} / \mathrm{m}^{3}$.

Flotation-oxal (flotoreagent-oxal, TU 38.103-249-80) must match the TU 38.103-429-83. Flotation reagent-oxal is a byproduct of isoprene production brought to the necessary condition through the stage of dimethyldioxane production. Introduction to the composition of the flotation agent-oxal allows you to change the structure of the foam plastic and improve its physical and mechanical properties.

As a result of experimental studies based on simplex planning [12, 13], the composition of PP was developed. The composition of the foam plastic \% mass:

phenol-formaldehyde resin $50-57 \%$

granules of polystyrene foam 
flotation reagent-oxal

$2-6 \%$

vermiculite

$26-31 \%$

the product of condensation of sulfadimidine with formaldehyde and

the rest orthophosphoric acid (VAH-3)

The main technological parameters of production foam plastic PP were worked out in laboratory conditions. The process of manufacturing PP is to prepare a reaction-active composition. Resin FRV-1A, flotation agent-oxal and foaming-curing agent VAH-3 is mixing with fillers (polystyrene and vermiculite). Then thermal insulation mass is laying in the form. Half the volume of the form is filled with prepared reaction-active composition. Foaming-curing agentVAH-3 and aluminum powder enter into an exothermic reaction. In the form starts process formation of foam plastic. The volume of the finished foam plastic is twice the volume of the original composition. The wall forms installed pressure gauge. During reaction of the foaming mold wall are under the pressure of 0-0.06 $\mathrm{MPa}$.

Process of production PP (TU 102-433-87) is characterized by the following parameters, it is shown in Table 2 .

Table 2 Parameters characterizing process of production PP

\begin{tabular}{ll}
\hline temperature of the product of $\mathrm{VAH}-3\left[{ }^{\circ} \mathrm{C}\right]$ & $20-22$ \\
temperature of resin FRV-1A and flotation agent-oxal $\left[{ }^{\circ} \mathrm{C}\right]$ & $20-25$ \\
room temperature $\left[{ }^{\circ} \mathrm{C}\right]$ & $18-20$ \\
form temperature $\left[{ }^{\circ} \mathrm{C}\right]$ & $30-40$ \\
time of mixing and laying the mixture into the mold $[\mathrm{S}]$ & $120-180$ \\
curing time of not less than $[\mathrm{S}]$ & 780 \\
the maximum temperature of the exothermic reaction $\left[{ }^{\circ} \mathrm{C}\right]$ & $100-105$ \\
the operating pressure during foaming $[\mathrm{MPa}]$ & 0.06 \\
\hline
\end{tabular}

Formation of crusts on the surfaces of the foam plastic causes its high mechanical properties $[14,15]$. Consider the mechanism of formation of these crusts.

The reactive composition merges into a mixer, where it is mixed with granules of polystyrene and vermiculite. From the mixer activated heat-insulating mass is discharged into the cassette and leveled. In the period of time from 180 to 600 seconds, the foaming reaction of the foam plastic occurs, during which hydrogen is released. Vermiculite particles can move in a liquid medium only in those first five minutes after the start of the foaming reaction, when the mixture is in a liquid state, then the foam is cured.

PP composition includes flotation reagent-oxal, which reduces the wetting angle of vermiculite with phenolformaldehyde resin by 2 times (from $30^{\circ}$ to $14^{\circ}$ ). More than 30 special additives were experimentally investigated, and only the flotation reagent-oxal observed selective property of floating vermiculite particles in the mixture to the surface. We assume that with the reduction of the vermiculite wetting angle by resin, the viscosity of the medium is equal to the viscosity of the liquid phase of the foaming system. There is an exothermic reaction, the temperature of the composition increases to $100{ }^{\circ} \mathrm{C}$. Already at 30 ${ }^{\circ} \mathrm{C}$, the viscosity of the polymer FRV-1A is equal to $1.1 \mathrm{~Pa} \cdot \mathrm{s}$.

The multiplicity of the foaming reaction mixture equal to 20 . The gas bubbles released during the reaction join the vermiculite particle, an effective particle is formed, the volume of which significantly exceeds the volume of the vermiculite particle (the volume of the PP composition is doubled, which is due to the bubbles of the released gas). The material becomes porous. Microscopic analysis confirms this hypothesis.

The mass of the effective particle is almost equal to the mass of the vermiculite particle 


$$
\frac{\rho_{\mathrm{g}}}{\rho_{\mathrm{b}}}=\frac{1.1}{2.86 \cdot 10^{3}}=3.85 \cdot 10^{-4},
$$

where $\rho_{v}$ - the density of vermiculite,

$\rho_{g}$ - the density of the gas.

The mode of motion of the effective particle located in the activated mixture is shown in Figure 1.

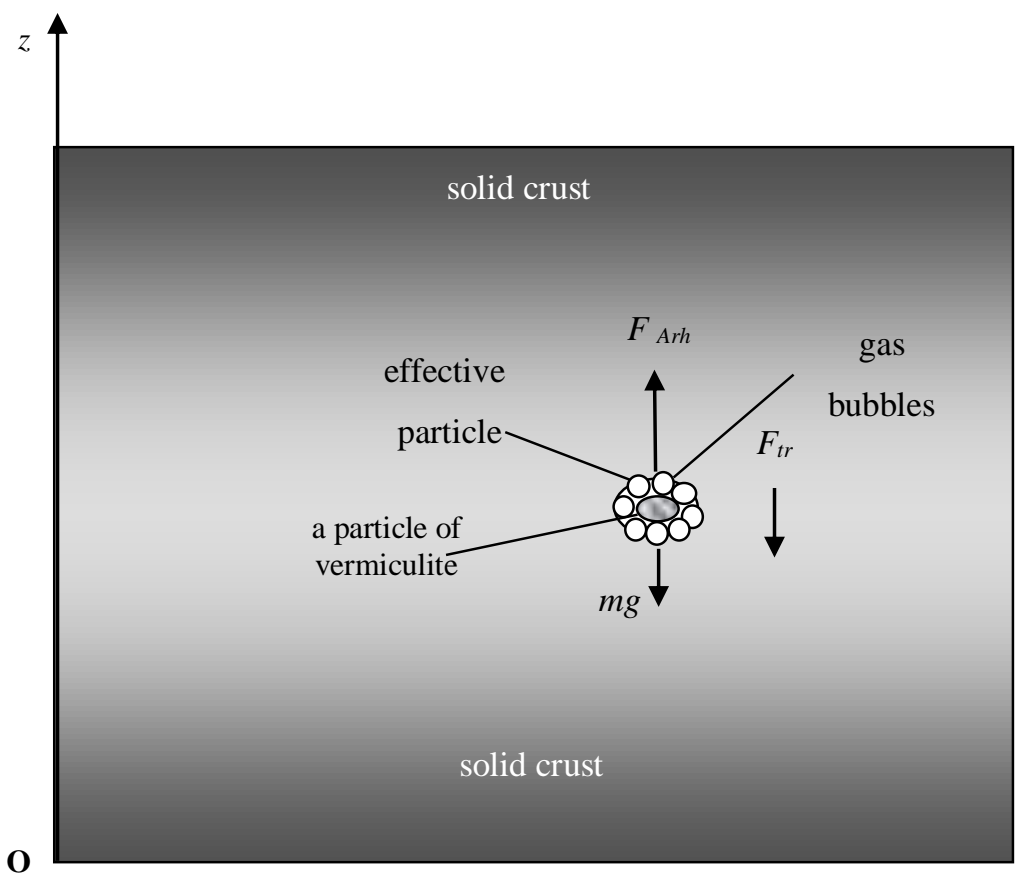

Fig. 1. Effective particle in the activated mixture.

The mode of movement of a single particle in reaction.

$$
m_{p} \frac{d v_{p}}{d t}=F_{A r h}-F_{t r}-m_{p} g,
$$

where $m_{p}$ - the mass of the particle,

$v_{p}$ - the speed of movement of the particle,

$\frac{d v_{p}}{d t}$ - acceleration of particle,

$F_{A r h}$ - the lifting force of Archimedes,

$F_{t r}$ - the force of resistance to motion of a particle.

In this case, in view of the small differences in the velocity of the interfacial surface of the carrier fluid, the reactive force will be neglected.

The particle mass $m_{p}=\frac{4}{3} \pi \cdot R_{p}^{3} \rho_{p}$ is a variable, it changes in time. Then 


$$
\frac{d m_{p}}{d t}=J
$$

where $J$ - is the rate of change of particle mass in time.

The speed of the particle movement is given by the equation

The resistance force

$$
\frac{d z_{p}}{d t}=v_{p}
$$

$$
F_{t r}=\frac{1}{2} C_{d} \rho_{l} v_{p}^{2} \frac{\pi \cdot d_{p}^{2}}{4}=-3 \pi \mu_{l} \rho_{l} d_{p} v_{p},
$$

where $C_{d}$ - the coefficient of resistance to movement, taking into account the influence of the mass transfer process, which in accordance with the law of Stokes is equal to $24 / R e$.

The change of free volume, which causes a change in the pressure in the mixture, is described by the equation

$$
d V_{g}=N \cdot d v_{p}
$$

where $N$ - is the number of particles in the liquid (it can be found by the initial concentration of the substance in the mixture),

$V_{g}$ - the volume of the gas released during the reaction.

Then the pressures in the mixture can be expressed:

$$
P V_{g}=u_{g} R_{\mathrm{g}} T_{\mathrm{g}}
$$

where $u_{\mathrm{g}}$ - the rate of change in the mass of gas in time,

$R_{\mathrm{g}}$ - gas constant.

The influence of chemical reactions on the dynamics of the rise of particles surrounded by a gas bubbles is taken into account by Archimedes' force, which is described by the equation:

$$
F_{A r h}=m_{p} g \frac{\rho_{l}}{\rho_{p}},
$$

where $\rho_{l}$ - the density of the environment,

$\rho_{p}-$ the density of the particle.

Vermiculite particle at a temperature of $20-105^{\circ} \mathrm{C}$ does not react with the components of the mixture. The change in the volume of the effective particle is due to gas. Therefore, the rate of change in the mass of the effective particle in time $J$ is close to zero:

$$
J \approx 0 .
$$

The time interval is small and therefore, the filtering effect can be not taken into account. The effective particle in the first approximation is considered to be non-reactive.

Solution of equation (2), with the initial condition that at $\mathrm{t}=180 \mathrm{~S}$ the particle is still stationary:

$$
v_{p}(180)=0,
$$

defines the speed at which the particle moves:

$$
v_{p}=\frac{m g}{3 \pi d \mu \rho_{l}}\left(\frac{\rho_{l}}{\rho_{p}}-1\right) \cdot\left(1-e^{3 \pi d \mu \rho_{l}(180-t)}\right) .
$$

Then the distance run by the effective particle is described by the equation: 


$$
\begin{gathered}
S(t)=\frac{m g}{3 \pi d \mu \rho_{l}} \cdot\left(\frac{\rho_{l}}{\rho_{p}}-1\right) \\
\left(T-180+\frac{1}{3 \pi d \mu \rho_{l}}\left(e^{3 \pi d \mu \rho_{l}(180-T)}-1\right)\right) .
\end{gathered}
$$

\section{Results and Discussion}

Vermiculite according to GOST 12865-67 is heterogeneous in composition and has an ellipsoidal configuration. The density of the vermiculite $2,52 \cdot 10^{3}-2,86 \cdot 10^{3} \mathrm{~kg} / \mathrm{m}^{3}$.

We study the behavior of a large fraction and determine the path that passes a large effective particle.

Let the average particle size vermiculite: $d_{1}=0.7 \cdot 10^{-2} ; d_{2}=0.5 \cdot 10^{-2} ; d_{3}=0.3 \cdot 10^{-2} \mathrm{~m}$. The mass of the particles of vermiculite:

$$
M=\frac{4 \pi}{3} \rho \cdot \frac{d_{1}}{2} \cdot \frac{d_{2}}{2} \cdot \frac{d_{3}}{2} ; \mathrm{M}=1.39 \cdot 10^{-4}-1.84 \cdot 10^{-4} \mathrm{~kg} .
$$

Then: the mass of the effective particle, which is determined by the mass of the vermiculite, is equal $1.4 \cdot 10^{-4}-1.6 \cdot 10^{-4} \mathrm{~kg}$. The density of the air is $1.2-0.95 \mathrm{kz} / \mathrm{m}^{3}$. The density of the resin FRV-1A $1.2 \cdot 10^{3} \mathrm{~kg} / \mathrm{m}^{3}$. The density of the product of VAH-3 $1.25 \cdot 10^{3} \mathrm{~kg} / \mathrm{m}^{3}$.

The ratio of the effective particle to volume of the vermiculite particle is equal to 2.96, the density of effective particle $8.5 \cdot 10^{2}-9.6 \cdot 10^{2} \mathrm{~kg} / \mathrm{m}^{3}$. The distance, that effective particle has passed after the beginning of foaming for $40 \mathrm{~s}$, we find from (12). It is $0.18-0.25 \mathrm{~m}$.

The ratio of the effective particle volume to the volume of the vermiculite particle is 1.54 , the density of the effective particle is $1.64 \cdot 10^{3}-1.86 \cdot 10^{3} \mathrm{~kg} / \mathrm{m}^{3}$. The distance, that effective particle has passed after the beginning of foaming for $40 \mathrm{~s}$, is negative: - 0.13 - (0.25) $m$. That is - she'll come down.

Thus, the bulk of vermiculite a minute after the beginning of foaming will be in the areas of formation of foam crusts. Microscopic analysis of the foam PP showed that only $12-18 \%$ vermiculite is distributed in the middle part of the product. The density of crust is more than $200 \mathrm{~kg} / \mathrm{m}^{3}$.

The density of the foam plastic in its middle part is $80 \mathrm{~kg} / \mathrm{m}^{3}$. The limit of strength at punching of the foam plastic PP by the rod diameter $0.01 \mathrm{~m}$ reaches $3.5 \mathrm{MPa}$, which is twice higher than that of the foam plastic FRP-I density $80 \mathrm{~kg} / \mathrm{m}^{3}$.

\section{Conclusions}

The foam plastic PP used for insulation of roofing panels, frame panels with an inner nonmetallic layer, is obtained. Such panels allow breaking bridges of cold in butt joints [16, 17, 18 ] that improves thermophysical characteristics, reliability and durability of the building as a whole[19, 20].

On the basis of the developed mathematical model [21-29] it is possible to predict the properties of PP foam plastic. 


\section{References}

1. B. Stefurak, L. Stefurak, Constr. pipel., 10 (1978)

2. B Aksenov, V. Mironov, S. Karyakina, I. Karyakin, Eng. Tech., 9 (9) (2018)

3. M. Chekardovskiy, V. Mironov, T. Zhilina, I. Shalagin, Civ. Eng. Techn., 9 (6) (2018)

4. O. Stepanov, B. Moiseev, M. Chekardovskiy, B. Aksenov, A. Shapoval, Appl. Eng. Res., 12 (20) (2017)

5. N. Kurilenko, D. Zverev, Gaz. Prom., 5 (2001)

6. G. Kuznetsov, N. Kurilenko, V. Maksimov, G. Mamontov, T. Nagornova, Eng. Phys. Therm., 86 (3) (2013)

7. S. Vyatkina, T. Zhilina, I. Molostova, V. Mironov, O. Stepanov, Civ. Eng. Techn., 9(9) (2018)

8. K. Vogrinec, M. Premrov, Eng. Struct., 175 ( 2018)

9. J. Havula, M. Garifullin, M. Heinisuo, K. Mela, S. Pajunen, Eng. Struct., 172 (2018)

10 A. Anandh, Eng. Appl. Scien., 13 (4) 2018

11 M. Garifullin, M. Bronzova, M. Heinisuo, K. Mela, S. Pajunen, Mag. Civ. Eng., 4 (2018)

12 M. Kirsanov, Mag. Civ. Eng., 1 (2015)

13 Y. Adler, Y. Granovsky. Methodology and practice of planning experiment in Russia. MISIS. (2016)

14 V. Vorobyev, B. Stefurak, L. Stefurak, Stroit. mat., 9 (1976)

15 B. Teja, A.Sengupta, Ind. Concr., 90 (9) 2016

16 V. Bindiganavile, N. Banthia, B. Aarup, ACI Mat. Jour., 99 (6) (2002)

17 B. Aksenov, A. Emelyanov, V. Ilyin, I. Molostova, M. Chekardovskiy, Appl. Eng. Res., 12 (20) (2017)

18 S. Korniyenko, N. Vatin, A. Gorshkov, Mag. Civ. Eng., 64 (2016)

19 A. Gorshkov, P. Rymkevich, Mag. Civ. Eng., 60, (2015)

20 R. Alihodzic, V. Murgul, N. Vatin, E. Aronova, V. Nikolić, M. Tanić, D. Stanković, Appl. Mech. Mat., 624, (2014)

21 A. Struchkova, Yu. Barabanshchikov, K. Semenov, A. Shaibakova, Civ. Eng., 78(2) (2018)

22 M. Petrichenko, D. Nemova, E. Kotov, D. Tarasova, V. Sergeev, Mag. Civ. Eng., 77(1) (2018)

23 D. Zaborova, G. Vieira, T. Musorina, A. Butyrin, Adv. Intell. Sys. Comput., 692 (2015)

24 K. Strogonov, A. Fedyukhin, T. Stepanova, O. Derevianko, Adv. Intell. Sys. Comput., 692 (2018)

25 N. Priadko, V.P. Mushchanov, H. Bartolo, N.I. Vatin, I.N. Rudnieva, Mag. Civ. Eng. 65, (2016)

26 M.R. Garifullin, A.V. Barabash, E.A. Naumova, O.V. Zhuvak, T. Jokinen, M. Heinisuo, Mag. Civ. Eng., 63, (2016)

27 A.Y. Struchkova, Yu.G. Barabanshchikov, K.S. Semenov, A.A. Shaibakova, Mag. Civ. Eng., 78 (2), (2018)

28 E. Gumerova, O. Gamayunova, L. Shilova, MATEC Web Conf., 106, (2017)

29 L.A. Karpenko, J.R. Nigmatulina, Teoriya i Praktika Fizicheskoy Kultury (2015) 